\title{
Management of intractable oronasal bleeding using Sengstaken-Blakemore tubes in patients with facial trauma: a case series and technical notes
}

\author{
Gi Woon Kim ${ }^{1}$, Sangchun $\mathrm{Choi}^{2}$, Sangsoo Han', Younghwan Lee', \\ Bora Kang ${ }^{3}$, Yoon Seok Jung ${ }^{2}$ \\ 'Department of Emergency Medicine, Soonchunhyang University Bucheon Hospital, Bucheon, Korea \\ ${ }^{2}$ Department of Emergency Medicine, Ajou University School of Medicine, Suwon, Korea \\ ${ }^{3}$ Department of Emergency Medical Technology, Masan University, Masan, Korea
}

Objective Intractable massive oronasal bleeding can become a life-threatening condition. The success rate of conventional bleeding control methods other than transarterial embolization (TAE) is not expected to be high. We investigated the efficacy of Sengstaken-Blakemore tube (SBT) balloon tamponade in patients with sustained and intractable oronasal bleeding secondary to facial injury.

Methods This study is a retrospective chart review from traumatic patients with sustained and intractable oronasal bleeding who were admitted to the emergency center of Ajou University Hospital and Soonchunhyang University Bucheon Hospital from January 2014 to December 2016.

Results Twelve patients were included in the study, of whom nine (75\%) were male. The median age was 31 years (range, 20-73 years). Bleeding was controlled in 11 of the 12 patients (91.7\%) either temporarily or definitively. One patient without hemostasis underwent TAE. TAE was performed in an additional three patients out of the 11 patients with hemostasis who experienced continued nasal bleeding after the removal of SBTs. There were no complications from performing the procedure.

Conclusion Using SBTs as a hemostatic tool will aid patients with life-threatening intractable oronasal bleeding. Furthermore, this method may be used in patients with continual and intractable oronasal bleeding after facial trauma as a bridging procedure from the emergency department or the intensive care unit to the interventional radiology.

Keywords Facial injuries; Epistaxis; Oral hemorrhage; Hemostasis
eISSN: 2383-4625

Received: 28 June 2020

Revised: 28 June 2020

Accepted: 12 August 2020

Correspondence to: Yoon Seok Jung Department of Emergency Medicine, Ajou University School of Medicine, 164 Worldcup-ro, Yeongton-gu, Suwon 16499, Korea

E-mail:ysjung@aumc.ac.kr

ORCID

https://orcid.org/0000-0002-0800-6250

Sangsoo Han

Department of Emergency Medicine, Soonchunhyang University Bucheon Hospital, 170 Jomaru-ro, Bucheon 14584, Korea

E-mail: brayden0819@schmc.ac.kr ORCID

https://orcid.org/0000-0002-9709-3332

This paper was presented as a poster at 2019 XVIIIth Congress of the European Shock Society and IXth Congress of the International Federation of Shock Societies.

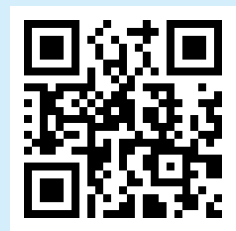

How to cite this article:

Kim GW, Choi S, Han S, Lee Y, Kang B, Jung YS. Management of intractable oronasal bleeding using Sengstaken-Blakemore tubes in patients with facial trauma: a case series and technical notes. Clin Exp Emerg Med 2021;8(1):65-70. https://doi.org/10.15441/ ceem. 20.079

This is an Open Access article distributed under the terms of the Creative Commons Attribution Non-Commercial License (https:// creativecommons.org/licenses/by-nc/4.0/). 


Capsule
Summary is already known
$\begin{aligned} & \text { The success rate of conventional oronasal bleeding control methods other than transarterial embolization is not ex- } \\ & \text { pected to be very high. Transarterial embolization requires specialized equipment, so it cannot be commonly performed } \\ & \text { in all institutions. }\end{aligned}$
$\begin{aligned} & \text { What is new in the current study } \\ & \text { Using Sengstaken-Blakemore tubes as a hemostatic tool will help the patients with life-threatening intractable orona- } \\ & \text { sal bleeding. Furthermore, this method may be used in the patients with intractable oronasal bleeding after as a bridg- } \\ & \text { ing procedure from the emergency department or the intensive care unit to interventional radiology. }\end{aligned}$

\section{INTRODUCTION}

Maxillofacial injury, accounting for $10 \%$ of all trauma patients, is often accompanied by numerous complications, such as airway compromise, intracranial hemorrhage, cervical spinal cord injury, and intractable oronasal bleeding. ${ }^{1}$ Intractable oronasal bleeding is life-threatening when the blood is aspirated or leads to airway obstruction and when hypovolemic shock occurs due to continual blood loss. ${ }^{2}$ At present, conventional treatment methods for oronasal bleeding secondary to facial trauma include anterior or posterior packing, maxillomandibular fixation (MMF), and transarterial embolization (TAE). ${ }^{3}$ The success rate of the aforementioned bleeding control methods is not expected to be high, except for TAE. However, not all institutions can perform TAE as it requires specialized equipment.

Sengstaken and Blakemore described the Sengstaken-Blakemore tube (SBT) as a salvage therapy for esophageal varix bleeding in 1950. ${ }^{4}$ The SBT has two inflatable balloons (esophageal balloon and gastric balloon) that compress the gastroesophageal junction and esophageal varices. The use of SBTs has declined due to the development of endoscopic technologies. ${ }^{5}$ However, it is still valuable for temporary bleeding control and hemostasis.

We hypothesize that the SBT is a useful hemostatic device for patients with oronasal bleeding secondary to facial injury. The esophageal and gastric balloons of the SBT play a role for tamponade, stabilizing the oronasal space. Morita et al. ${ }^{6}$ reported the successful control of sustained and intractable nasal bleeding using an SBT for tamponade in a patient with maxillofacial injury. Therefore, we investigated the experience of SBT balloon tamponade in patients with sustained and intractable oronasal bleeding secondary to facial injury.

\section{METHODS}

This study is a retrospective chart review from consecutive traumatic patients with sustained and intractable oronasal bleeding who were admitted to the emergency center of Ajou University Hospital and Soonchunhyang University Bucheon Hospital from January 2014 to December 2016. This study was approved by the institutional review board of Soonchunhyang University Bucheon Hospital (2018-12-008-001). Informed consent was waived due to the retrospective nature of chart review study. The inclusion criteria were age $\geq 18$ years old, blunt trauma, facial injury with a face abbreviated injury scale score $\geq 3$, transfusion of $\geq 3$ units of packed red blood cells within 24 hours, and insertion of an SBT for hemostasis. We excluded patients who were pregnant or had a history of hematologic disease and patients with other organ injuries, e.g., hemothorax, hemoperitoneum, and fractures involving the major extremities.

We inserted SBTs into the patients to manage their life-threatening oronasal bleeding secondary to facial injury at emergency departments. Prior to the procedure, all patients received advanced airway management, such as endotracheal intubation, and the balloons of an SBT were tested for defects. We performed the procedure under aseptic conditions with a surgical drape, gown, sterile gloves, a mask, and headcover. The SBT was cautiously inserted along the floor of the nasal cavity and was aimed at the patient's mandibular angle to prevent a possible basal skull fracture. This process was crucial for avoiding the significant fracture involving the midface and aggravated or displaced cribriform plate. Subsequently, the SBT was secured inside the oral cavity with its tip held firmly at the oropharynx. A second SBT was inserted into the other nasal cavity in the same manner (Fig. 1). First, both gastric balloons were inflated at the same time with a volume of 100 to $150 \mathrm{~mL}$. Then, the esophageal balloons were in- 
flated with a volume of 50 to $80 \mathrm{~mL}$ (Fig. 1). Inserted SBTs to the patients and brain computed tomography after insertion of SBT were depicted in Figs. 2 and 3.

We retrospectively investigated age, sex, mechanism of injury, diagnosis, laboratory findings, success rate of the procedure, initial vital signs including the Glasgow Coma Scale (GCS), and mortality. The success of the procedure was determined by visual as-
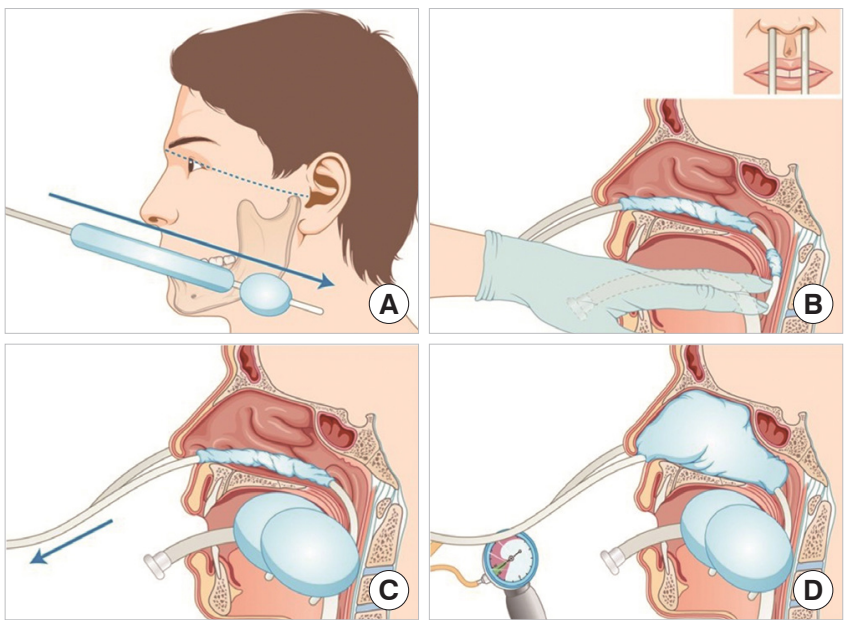

Fig. 1. Sengstaken-Blakemore tube application procedure for controlling intractable oronasal bleeding. (A) Insertion toward the mandible angle. (B) Grasping the Sengstaken-Blakemore tube tip at the pharynx. (C) Inflation of the gastric balloon. (D) Inflation of the esophageal balloon.
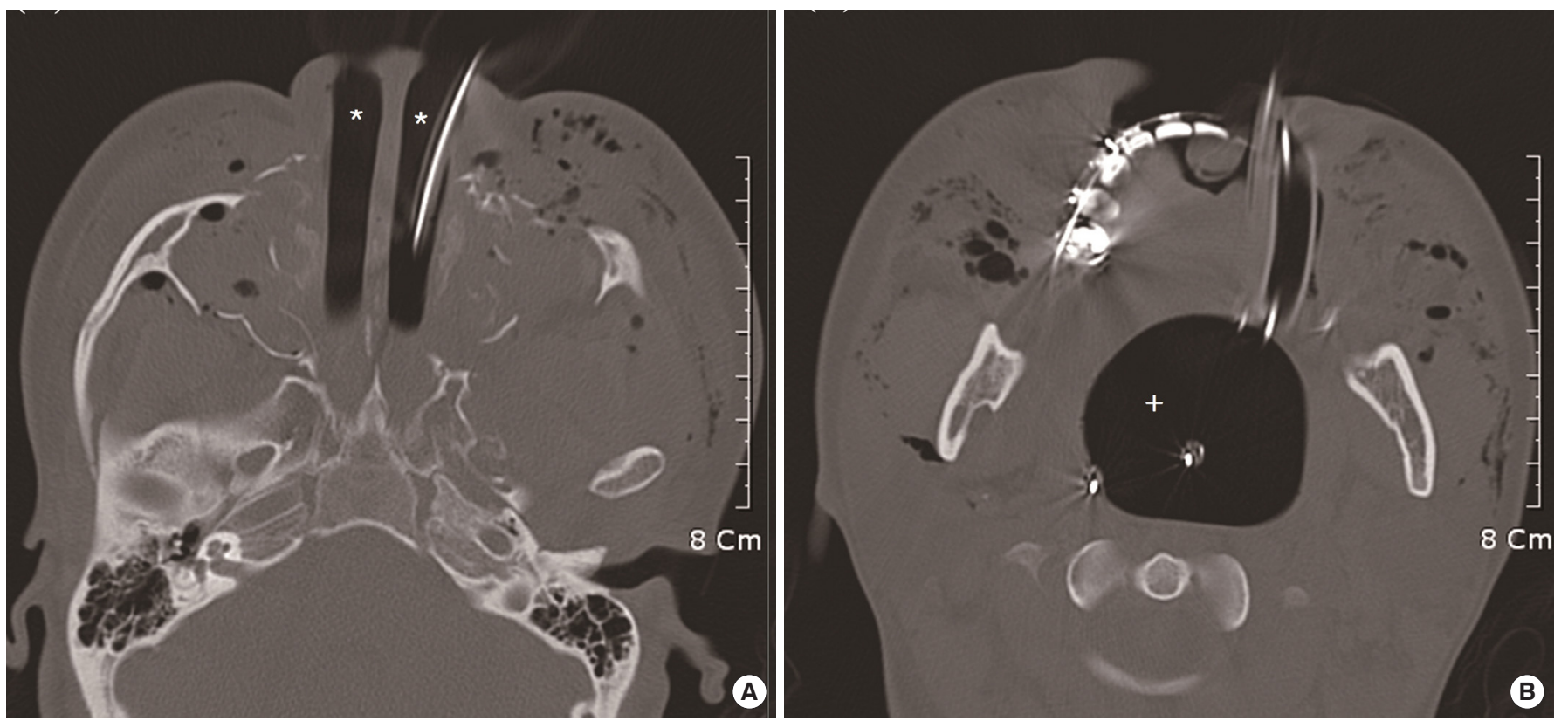

Fig. 3. Brain computed tomography scan images of a patient who received the Sengstaken-Blakemore tubes. (A) Inflated esophageal balloons ${ }^{*}$ ) in the nasal cavity. (B) inflated gastric balloon (+) in the oral cavity. Informed consent for publication of the clinical image was obtained from the patient. 
Table 1. Demographic characteristics of patients with life-threatening intractable oronasal bleeding

\begin{tabular}{|c|c|c|c|c|c|c|c|c|c|c|c|c|c|c|c|}
\hline \multirow[b]{2}{*}{ Case } & \multirow{2}{*}{$\begin{array}{l}\text { Age/ } \\
\text { sex }\end{array}$} & \multirow[b]{2}{*}{ Mechanism } & \multirow{2}{*}{$\begin{array}{l}\text { Diagnosis } \\
\text { (fractures) }\end{array}$} & \multicolumn{4}{|c|}{ Pre-SBT } & \multirow{2}{*}{$\begin{array}{c}\text { RBC } \\
\text { (units) }\end{array}$} & \multicolumn{3}{|c|}{ Post-SBT (3 hr) } & \multirow[b]{2}{*}{$\mathrm{E}$} & \multicolumn{3}{|c|}{ Result } \\
\hline & & & & GCS & $\begin{array}{c}\mathrm{BP} \\
(\mathrm{mmHg})\end{array}$ & HR & $\begin{array}{c}\mathrm{Hb} \\
(\mathrm{g} / \mathrm{dL})\end{array}$ & & $\begin{array}{c}\text { BP } \\
(\mathrm{mmHg})\end{array}$ & $\mathrm{HR}$ & $\begin{array}{c}\mathrm{Hb} \\
(\mathrm{g} / \mathrm{dL})\end{array}$ & & $\mathrm{CPC}$ & D & $\begin{array}{l}\text { TाD } \\
(\mathrm{hr})\end{array}$ \\
\hline 1 & $20 / \mathrm{F}$ & TA Passenger & $\mathrm{B}, \mathrm{O}, \mathrm{N}, \mathrm{Z}, \mathrm{Mx}, \mathrm{Mn}$ & 15 & $106 / 70$ & 117 & 12.6 & 4 & $119 / 73$ & 112 & 7.3 & + & 1 & & \\
\hline 2 & $29 / \mathrm{M}$ & TA Driver & $\mathrm{B}, \mathrm{O}, \mathrm{N}, \mathrm{Mx}$ & 7 & $140 / 59$ & 116 & 12.6 & 14 & $142 / 75$ & 99 & 12.5 & & 5 & + & 1,329 \\
\hline 3 & $73 / \mathrm{M}$ & TA Pedestrian & $0, N, Z, M x$ & 11 & $142 / 75$ & 100 & 8.9 & 16 & $65 / 46$ & 96 & 5.9 & + & 3 & & \\
\hline 4 & $27 / M$ & Fall $10 \mathrm{~m}$ & $\mathrm{~B}, \mathrm{O}, \mathrm{N}, \mathrm{Mx}, \mathrm{Mn}$ & 3 & $86 / 47$ & 148 & 14.1 & 17 & $106 / 53$ & 118 & 7.2 & & 5 & + & 40 \\
\hline 5 & $42 / \mathrm{M}$ & TA Driver & $0, N, Z, M x, T, S$ & 3 & $53 / 31$ & 88 & 9 & 14 & $81 / 50$ & 94 & 10 & & 5 & + & 9 \\
\hline 6 & $29 / \mathrm{M}$ & TA Driver & $0, N, Z, M x, M n$ & 15 & $140 / 59$ & 116 & 11.2 & 18 & $142 / 75$ & 99 & 11.5 & & 1 & & \\
\hline 7 & $43 / \mathrm{M}$ & Fall $8 \mathrm{~m}$ & $0, N, Z, M x, M n$ & 15 & $75 / 40$ & 120 & 9.6 & 7 & $140 / 85$ & 125 & 8.5 & & 1 & & \\
\hline 8 & $54 / F$ & TA Pedestrian & $B, N, M x, S$ & 7 & $95 / 54$ & 68 & 9.8 & 5 & $110 / 75$ & 100 & 11.5 & + & 5 & + & 678 \\
\hline 9 & $33 / \mathrm{M}$ & TA Driver & $\mathrm{N}, \mathrm{Z}, \mathrm{Mn}, \mathrm{S}$ & 14 & $78 / 56$ & 112 & 13.5 & 10 & $95 / 60$ & 113 & 13.5 & & 1 & & \\
\hline 10 & $25 / F$ & Fall $12 \mathrm{~m}$ & $\mathrm{~B}, \mathrm{O}, \mathrm{N}, \mathrm{Z}, \mathrm{Mx}, \mathrm{T}, \mathrm{S}$ & 3 & $0 / 0$ & 0 & 16.3 & 13 & $73 / 54$ & 60 & 11.3 & & 5 & + & 7 \\
\hline 11 & $54 / \mathrm{M}$ & TA Passenger & $B, O, N, Z, M x, M n, T, S$ & 11 & $60 / 30$ & 110 & 10.3 & 7 & $130 / 73$ & 120 & 11.5 & + & 3 & & \\
\hline 12 & $29 / M$ & Fall $7 \mathrm{~m}$ & $\mathrm{~N}, \mathrm{Z}, \mathrm{Mx}, \mathrm{Mn}$ & 11 & $121 / 81$ & 110 & 6.8 & 8 & $130 / 93$ & 123 & 10.7 & & 3 & & \\
\hline
\end{tabular}

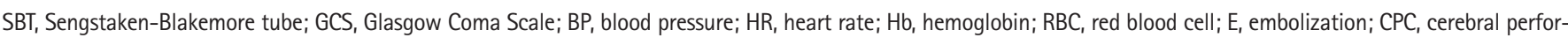
mance category; $\mathrm{D}$, death; TT, time to death; TA, traffic accident; $\mathrm{B}$, basal bone; $\mathrm{O}$, orbital bone; $\mathrm{N}$, nasal bone; $\mathrm{Z}$, zygoma; Mx, maxillary bone; Mn, mandible; T, temporal bone; $S$, sphenoid.

\section{RESULTS}

This study included 12 patients, of whom nine were male (75\%). The median age was 31 years (range, 20-73 years). Table 1 represents a study summary.

We managed either to control bleeding temporarily or definitively in 11 of the 12 patients (91.7\%). One patient without hemostasis underwent TAE (case 3). TAE was performed in an additional three out of the 11 patients with hemostasis who experienced continued nasal bleeding after the removal of SBTs (cases 1,8 , and 11).

One female patient was in cardiac arrest upon arrival at the hospital (case 10). The return of spontaneous circulation was achieved through cardiopulmonary resuscitation. SBTs were inserted to stop oronasal bleeding. Despite stopping the bleeding, cardiac arrest reoccurred due to a severe head injury. The patient died 7 hours post-arrival at the hospital.

The overall mortality rate was $41.6 \%$. Hypovolemia was not the cause of death. Two of the patients died of disseminated intravascular coagulation (cases 2 and 8), and three patients died from severe head injuries (cases 4, 5, and 10). The time to death from hospital arrival ranged from 7 to 1,329 hours. The initial GCS scores for the expired patients were below 8. The GCS scores were 7 for two patients and 3 for three patients. Four of the seven survivors were discharged with a cerebral performance category (CPC) score of 1 , and three survivors had a CPC score of 3.

The average initial hemoglobin level for the 12 patients was $11.33 \mathrm{~g} / \mathrm{dL}$. Three hours after the insertion of SBTs, the average was $10.17 \mathrm{~g} / \mathrm{dL}$. An average of 11.8 packed red blood cells was transfused within 24 hours.

Mean arterial pressure improved (average change from 60.82 to $84.73 \mathrm{mmHg}$ ) 3 hours after the SBT insertion in 11 patients with successful hemostasis. Heart rate did not significantly change after the successful hemostasis, with the average change from 100.45 to 105.73 beats/min.

No complications, e.g., malposition of the tube and necrosis of the mucous membrane, were reported in the patients who underwent the SBT procedure.

\section{DISCUSSION}

Sustained and intractable oronasal bleeding after blunt facial injury is rare. ${ }^{7}$ This condition however, can be life-threatening when there is sustained bleeding due to facial bone fractures. Thus, the bleeding must be stopped immediately. In our study, the rate of successful bleeding control was $91.7 \%$. This rate is much higher than that of previous reports. ${ }^{8-10}$ Based on this result; we believe that bleeding control using SBTs will be useful in situations where specialized treatments, such as TAE and MMF, cannot be performed immediately in under-equipped facilities.

Initial attempts to control the bleeding are carried out typically using non-invasive and easily applicable methods like gauze packing. This type of method uses a nasal tampon approach to compress the bleeding site directly with gauze packing, a urinary catheter, or Bellocq tamponade. However, their reported success rates for bleeding control are relatively low, ranging from $47 \%$ to $79 \% \%^{9-11}$ This indicates a frequent failure to achieve hemostasis in these patients. 
The subsequent selections for consideration to control the bleeding are MMF or TAE. Bleeding control by TAE in cases of maxillofacial bone fractures has shown a high success rate of 90\% owing to the recent development of transvascular interventions, such as embolization. ${ }^{12,13}$ Embolization, however, is not available in all hospitals, and preparation for performing this procedure is timeconsuming. As such, death can befall hemodynamically unstable patients during the waiting period prior to the embolization. Therefore, our swift and simple method will be significantly beneficial to these patients.

In our study, SBTs were applied as a hemostatic procedure, which met the conditions mentioned above. The success rate of hemostasis was $91.7 \%$, and all patients were stabilized hemodynamically. However, three patients underwent TAE because of prolonged bleeding following tube withdrawal.

Our method has the following advantages. First, the chance of success in controlling continual oronasal bleeding is high. Bleeding control can be achieved by dual functions of the balloons, i.e., direct compression on the bleeding sites as well as stabilization and temporary traction around the oronasal cavity. In many cases, the main culprit of sustained and intractable oronasal bleeding is the oral cavity that contains soft tissues only and no solid structures. ${ }^{14}$ Thus, typical packing methods do not work effectively in the oral cavity. We believe that the two bilateral gastric balloons of the SBTs create a valid tamponade state by buttressing against each other within the oral cavity. Second, the esophageal balloon is sufficiently large to tamponade the nasal cavity entirely. Since two SBTs were used in our method, both tamponade and temporary traction around the nasal cavity structures would be expected. Additionally, in our study, the gastric balloon of the SBT was inflated in the oral cavity, and the esophageal balloon was inflated in the nasal cavity for compression of the bleeding site. Previously, Morita et al. ${ }^{6}$ used a similar method to ours. They inflated the esophageal balloon as a tamponade in the nasal cavity and the gastric balloon in the oropharynx. The difference between our method and theirs is the position of the gastric balloon, which is the oral cavity and the oropharynx, respectively. The question might arise whether the inflated esophageal balloon can fill the nasal cavity entirely and press against the bleeding points. Morita et al. ${ }^{6}$ demonstrated that the balloon compressed the entire nasal cavity perfectly based on the model that they created to prove SBTs' usefulness for uncontrolled nasal bleeding, especially when there is a lack of knowledge about the exact bleeding location. Third, the intervention center for embolization requires expensive equipment, infrastructure, and an experienced team. In contrast, the SBT can be performed in an ordinary hospital setting by physicians who are experienced with careful balloon catheter insertion. Hemostasis with an SBT has a short learning curve and does not require special infrastructure. The SBT is less costly than MMF or TAE. Fourth, multiple bleeders and soft tissue injuries are common in patients with blunt facial trauma. To prevent the necrosis of injured soft tissues, selective angiographic embolization may be needed. ${ }^{15}$ Fifth, the esophageal and gastric balloons may temporarily be used to apply traction and stabilize the displaced fracture and injured soft tissues. This traction and stabilization may have a similar effect to that by MMF. Sixth, the direct compression by the gastric balloon within the oral cavity decreased the development of edema in the soft palate and other soft tissues in the oral cavity that are caused by the blood and the aspiration to the trachea.

Possible complications are as follows. First, the direct compression on the soft tissues may cause soft tissue necrosis. It could be prevented by regularly deflating the balloons, or as needed, and re-inflating them. Second, for severe fractures like basal skull fracture and le Fort III, fracture displacement can be aggravated by the insertion of the SBT tube. Therefore, the procedure protocol should be thoroughly followed.

Life-threatening hemorrhage is defined as the loss of three units of blood in 2 hours and a decrease in the hematocrit level to less than $21 \% .{ }^{16}$ In our study, all patients were transfused with more than four units of red blood cells and were categorized as class II or higher according to the Advanced Trauma Life Support classification of hypovolemic shock. ${ }^{17}$ In cases with a large amount of bleeding, the bleeding must be stopped immediately. Nasal tamponade by the SBT was able to control the bleeding in 11 patients. Five patients died, but their deaths were not attributed to hypovolemia. In addition, four of seven patients (57.1\%) were discharged with a CPC score of 1. The CPC score was originally a measure of brain ischemia after cardiac arrest. In our study, we used the CPC to determine the degree of disability at the time of discharge. ${ }^{18}$ The initial GCS score may be related to the outcome of survival because patients with an initial GCS score of lower than 8 are the only deceased. Conversely, patients with an initial GCS score higher than 13 were discharged with a CPC score of 1.

Our present study has several limitations. First, this study had a retrospective design that used medical records. Second, the number of patients included in the study was not sufficiently large, since the incidence of uncontrolled epistaxis due to facial trauma was 9.4\%.,19 The sample size was further reduced due to the exclusion criteria (patients with other organ injuries, etc.). Therefore, the usefulness of our proposed method requires verification in a large-scale prospective study.

In summary, using SBTs as a hemostatic tool may be considered an option for the management of life-threatening intracta- 
ble oronasal bleeding in the case of immediate unavailability of TAE. Furthermore, this method could be used in patients with lifethreatening intractable oronasal bleeding after facial trauma as a bridging procedure from the emergency department or the intensive care unit to the interventional radiology suite. Further investigation is necessary to evaluate the efficacy of using SBTs as a hemostatic tool in patients with traumatic and intractable oronasal bleeding.

\section{CONFLICT OF INTEREST}

No potential conflict of interest relevant to this article was reported.

\section{REFERENCES}

1. Chen CC, Jeng SF, Tsai HH, Liliang PC, Hsieh CH. Life-threatening bleeding of bilateral maxillary arteries in maxillofacial trauma: report of two cases. J Trauma 2007;63:933-7.

2. Liu WH, Chen YH, Hsieh CT, Lin EY, Chung T, Ju DT. Transarterial embolization in the management of life-threatening hemorrhage after maxillofacial trauma: a case report and review of literature. Am J Emerg Med 2008;26:516.

3. Cogbill TH, Cothren CC, Ahearn MK, et al. Management of maxillofacial injuries with severe oronasal hemorrhage: a multicenter perspective. J Trauma 2008;65:994-9.

4. Sengstaken RW, Blakemore AH. Balloon tamponage for the control of hemorrhage from esophageal varices. Ann Surg 1950;131:781-9.

5. Bosch J, Abraldes JG, Berzigotti A, Garcia-Pagan JC. Portal hypertension and gastrointestinal bleeding. Semin Liver Dis 2008;28:3-25.

6. Morita S, Shibata M, Nakagawa Y, Yamamoto I, Inokuchi S. Successful hemostasis of intractable nasal bleeding with a Sengstaken-Blakemore tube. Otolaryngol Head Neck Surg 2006;134:1053-4.

7. Tung TC, Tseng WS, Chen CT, Lai JP, Chen YR. Acute life-threat- ening injuries in facial fracture patients: a review of 1,025 patients. J Trauma 2000;49:420-4.

8. Sakamoto T, Yagi K, Hiraide A, et al. Transcatheter embolization in the treatment of massive bleeding due to maxillofacial injury. J Trauma 1988;28:840-3.

9. Ardekian L, Samet N, Shoshani Y, Taicher S. Life-threatening bleeding following maxillofacial trauma. J Craniomaxillofac Surg 1993;21:336-8.

10. Shimoyama T, Kaneko T, Horie N. Initial management of massive oral bleeding after midfacial fracture. J Trauma 2003;54: 332-6.

11. Iqbal M, Ahmed W. Epistaxis: its prevalence in IDPs of North Waziristan Agency. Am J Clin Exp Med 2015;3:233-6.

12. Noy D, Rachmiel A, Emodi O, Amsalem Y, Israel Y, Nagler RM. Transarterial embolization in maxillofacial intractable potentially life-threatening hemorrhage. J Oral Maxillofac Surg 2017; 75:1223-31.

13. Choi SC, Jung JY, Lee KJ, Won JH, Cho JP. Radiologic intervention for traumatic epistaxis. J Korean Soc Emerg Med 2003;14: 137-40.

14. Jose A, Nagori SA, Agarwal B, Bhutia O, Roychoudhury A. Management of maxillofacial trauma in emergency: an update of challenges and controversies. J Emerg Trauma Shock 2016;9: 73-80.

15. Ntomouchtsis A, Venetis G, Zouloumis L, Lazaridis N. Ischemic necrosis of nose and palate after embolization for epistaxis: a case report. Oral Maxillofac Surg 2010;14:123-7.

16. Samama CM. Traumatic emergencies and hemostasis. Cah Anesthesiol 1995;43:479-82.

17. Mutschler M, Nienaber U, Brockamp T, et al. A critical reappraisal of the ATLS classification of hypovolaemic shock: does it really reflect clinical reality? Resuscitation 2013;84:309-13.

18. Brain Resuscitation Clinical Trial I Study Group. Randomized clinical study of thiopental loading in comatose survivors of cardiac arrest. N Engl J Med 1986;314:397-403.

19. Frable MA, El-Roman N, Lenis A, Hung JP. Hemorrhagic complications of facial fractures. Laryngoscope 1974;84:2051-7. 